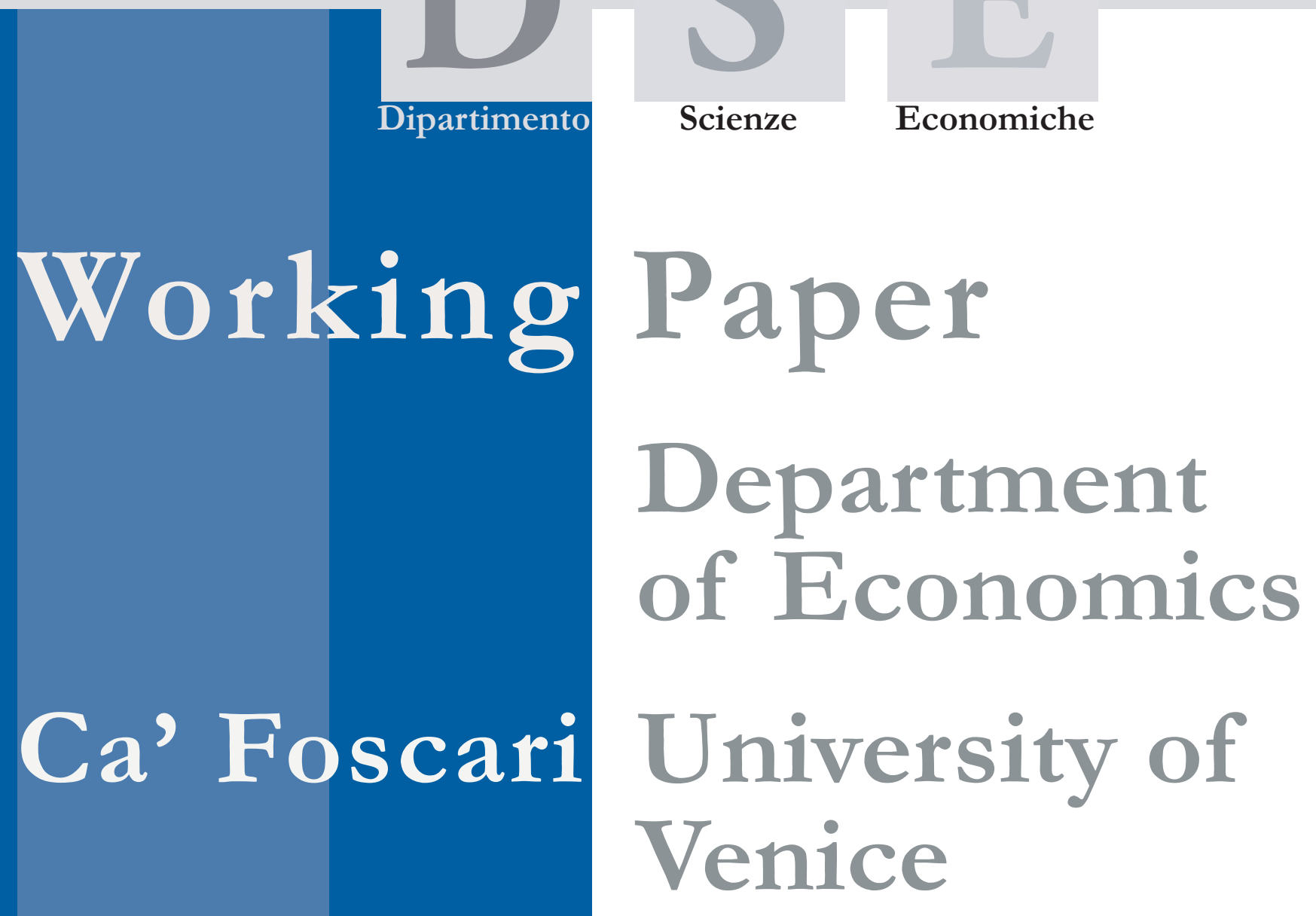

Francesco Bosello

Carlo Carraro

Enrica De Cian

Climate policy and the Optimal balance between Mitigation, Adaptation and Unavoided Damage 


\title{
Q. \\ Climate Policy and the Optimal Balance between Mitigation, Adaptation and Unavoided Damage
}

\author{
Francesco Bosello \\ University of Milan and Fondazione ENI Enrico Mattei
}

Carlo Carraro

University Ca’ Foscari of Venice and Fondazione ENI Enrico Mattei

Enrica De Cian

University Ca’ Foscari of Venice and Fondazione ENI Enrico Mattei

This draft: February 2010

\begin{abstract}
It has become commonly accepted that a successful climate strategy should compound mitigation and adaptation. The accurate combination between adaptation and mitigation that can best address climate change is still an open question. This paper proposes a framework that integrates mitigation, adaptation, and climate change residual damages into an optimisation model. This set-up is used to provide some insights on the welfare maximising resource allocation between mitigation and adaptation, on their optimal timing, and on their marginal contribution to reducing vulnerability to climate change. The optimal mix between three different adaptation modes (reactive adaptation, anticipatory adaptation, and investment in innovation for adaptation purposes) within the adaptation bundle is also identified. Results suggest that the joint implementation of mitigation and adaptation is welfare improving. Mitigation should start immediately, whereas adaptation somehow later. It is also shown that in a world where the probability of climate-related catastrophic events is small and where decision makers have a high discount rate, adaptation is unambiguously the preferred option. Adaptation needs, both in developed and developing countries, will be massive, especially during the second half of the century. Most of the adaptation burden will be on developing countries. International cooperation is thus required to equally distribute the cost of adaptation.
\end{abstract}

Keywords

Climate change impacts, mitigation, adaptation, integrated assessment model

JEL Codes

Q54, Q56, Q43

This paper has been prepared for the Copenhagen Consensus 2009. AD-WITCH, the model used in this study, has been developed by FEEM in cooperation with the OECD. The authors gratefully acknowledge their financial support. They are also grateful to Shardul Agrawala, Rob Dellink, Kelly de Bruin and Richard Tol for helpful comments. Nonetheless, the views expressed in this paper are the authors' sole responsibility. Finally, the contribution of all colleagues who worked on the development of the original WITCH model - in particular Valentina Bosetti, Emanuele Massetti, and Massimo Tavoni - is gratefully acknowledged.

This Working Paper is published under the auspices of the Department of Economics of the Ca' Foscari University of Venice. Opinions expressed herein are those of the authors and not those of the Department. The Working Paper series is designed to divulge preliminary or incomplete work, circulated to favour discussion and comments. Citation of this paper should consider its provisional character.

The Working Paper Series is available only on line (www.dse.unive.it/pubblicazioni) For editorial correspondence, please contact: wp.dse@unive.it
Department of Economics

Ca' Foscari University of Venice

Cannaregio 873, Fondamenta San Giobbe

30121 Venice Italy

Fax: ++390412349210 


\section{Introduction}

Ambitious mitigation actions are essential to reduce future climate change and the related irreversible and potentially catastrophic consequences. However, these cannot be avoided completely. Average temperature is already $0.7^{\circ} \mathrm{C}$ above the pre-industrial level and, given the latest developments of international climate change negotiations, additional warming cannot be excluded. To some extent, short-term and medium-term temperature increases are already predetermined, as well as the associated damages. The Fourth Assessment Report (Solomon et al. 2007, Parry et al. 2007) emphasised how an already moderate warming of 2 degrees would affect our lifestyle and produce negative, though not catastrophic, consequences.

The 2 degree Celsius climate target is unlikely to be achieved (Parry 2009, Carraro and Massetti 2010) and policies of adaptation and recovery capable of dealing at least with this amount of damage become essential. This awareness was recalled in the Copenhagen Accord, during the last round of international negotiations. The document recognises that climate change has already caused adverse impacts. Together with the need of containing global warming below $2{ }^{\circ} \mathrm{C}$, it requires a comprehensive programme on adaptation, including international support for developing countries.

Since the first indications contained in the 1997 Kyoto Protocol, iterated in Marrakech in 2001, and strengthened in Bali in 2007, the growing emphasis on adaptation witnesses the political and scientific consensus of the necessity of a joint mitigation and adaptation effort. It also raises a set of still unanswered questions concerning the design of the optimal mix between the two measures. Insights are to be provided on the optimal resource allocation between mitigation and adaptation, on their optimal timing and on their marginal contribution to reducing vulnerability to climate change. However, a consolidated framework that explicitly models the connections between mitigation, climate change impacts, and adaptation is still missing.

Introducing adaptation into numerical models is very important to quantify adaptation needs under different mitigation and climate change damage scenarios, and it is also challenging. A major difficulty relates to the different nature of mitigation and adaptation. The former falls into the category of international policies. Mitigation policies are typically studied with international macroeconomic models and implemented through large-scale tax-quota schemes. On the contrary, 
adaptation policies often take the form of project-based activities with a local, site-specific relevance. As a consequence, the usual approach to adaptation has a microeconomic perspective. Reconciling the two views is problematic, but at the same time necessary. To derive strategic longterm policy insights, the interaction between adaptation and mitigation must be analysed with a macroeconomic angle.

Against this background, this paper proposes an integrated assessment-modelling framework for the macroeconomic analysis of adaptation and mitigation, AD-WITCH. Adaptation contains a portfolio of macro-strategies that describe specific features of adaptation measures. In this setting, anticipatory adaptation, reactive adaptation, and investment in adaptation $R \& D$ take the form of dedicated investments or expenditure flows. When implemented, they decrease climate change damages, but at a cost. Adaptation competes with mitigation and other investments in the process of utility maximisation in a full cost-benefit framework. Using this set-up, the optimal composition and timing of climate change strategies are assessed. Emphasis is given not only to the dichotomy between mitigation and adaptation, but also to the role of different adaptation typologies and to their regional specificities. An additional contribution of this paper to the limited literature in the field is its updated calibration of climate change damages and of adaptation costs and benefits.

The remainder of the paper is organised as follows. Section 2 briefly reviews the related literature. Section 3 describes the adaptation module of the AD-WITCH model and its calibration. Section 4 presents main findings. Finally, section 5 summarises and concludes.

\section{The joint assessment of mitigation and adaptation in the existing modelling literature}

The modelling literature that relates to the present research is still at an initial stage ${ }^{1}$. To our knowledge it is confined to the contributions of Hope (1993, 2006), Bosello (2008), de Bruin et al. (2007), de Bruin, Dellink and Agrawala (2009).

In the PAGE model (Hope 1993, 2006) adaptive policies can operate in three ways. They can increase the slope of the tolerable temperature profile or its plateau. They can also reduce the adverse impacts of climate change when temperature exceeds the tolerable threshold. Adaptation is

\footnotetext{
${ }^{1}$ In this we disregard the vast literature dealing with adaptation cost and effectiveness at the site-level.
} 
exogenously imposed and costs and benefits are given. The default adaptation strategy is very effective because benefits are assumed to be large. Impact reduction through adaptation ranges between $90 \%$ in the OECD to $50 \%$ in other regions. Globally, adaptation can achieve a damage reduction of roughly US\$ 35 trillion at the cost of US\$ 3 trillion, within the period 2000-2200 using a 3\% discount rate. With these assumptions, it not surprising that PAGE can easily justify aggressive adaptation policies (Hope et al. 1993), implicitly decreasing the appeal of mitigation. It is worthy emphasising that, in PAGE, adaptation is exogenous. It is not determined inside the model as a choice variable, but it is a scenario variable decided from the outset. As a consequence, the model cannot provide information about the dynamic optimal combination between mitigation and adaptation.

De Bruin, Dellink and Tol (2009), enriched the DICE model (Nordhaus 1994) with global cost and benefit functions of adaptation. Adaptation is a flow variable that needs to be adjusted period by period because it does not address future damages. That paper showed that adaptation and mitigation are strategic complements. The optimal policy consists of a mixture between adaptation measures and mitigation investments. This mix is optimal also in the short-term, even though mitigation will only decrease damages in later periods. Adaptation is the main climate change costreducer until 2100 whereas mitigation prevails afterwards. In addition, the benefits of adaptation are higher than those of mitigation until 2130. The trade-off between strategies is also highlighted.

The introduction of mitigation decreases the need to adapt and vice versa. .However, the second effect is stronger than the first. Mitigation reduces the environmental damage stock only marginally and therefore it has a limited impact on the need to adapt, which remains significant particularly during the first decades. Sensitivity analysis over the different discount rates indicates that lower values favour mitigation over adaptation. Intuitively lower discount rates increase the relative weight of future damages, favouring mitigation, which is more effective in the long-term.

All these results are consolidated in de Bruin, Dellink and Agrawala (2009), which repeated the analysis with an updated calibration of adaptation costs and benefits and proposed also regional details, using the RICE model. In terms of utility, adapting is better than mitigating when damages are low. The reverse occurs when damages increase. In this case, mitigation is the preferred option to avoid higher, long-term damages.

Bosello (2008) compared adaptation and mitigation in a similar setting, using the FEEM-RICE model with endogenous technical progress (Buonanno et al. 2000). Differently from de Bruin, 
Dellink and Tol (2009) and de Bruin, Dellink and Agrawala (2009), adaptation is modelled as a stock of defensive capital that is accumulated over time with periodical protection investments. In that setting, mitigation should be optimally anticipated to early periods and adaptation should be postponed to later stages. This is the first key qualitative difference with previous contributions. The main damage reducer in early stages is mitigation and not adaptation. Mitigation has to be anticipated because of its delayed effects driven by environmental inertia. Adaptation can be postponed because it is rapidly effective. When damage stock is low, it is not worthy to reduce consumption and to invest in adaptation. This strategy becomes cost-efficient only when the stock of damage is sufficiently large. The second important difference is that larger damages increase both adaptation and mitigation, but the relative contribution of adaptation becomes larger. This result depends on the different nature of adaptation, which in Bosello (2008) is a stock variable. Adaptation has an effect that cumulates over time and therefore it is more cost-effective than in the setting proposed by de Bruin, Dellink and Tol (2009), where adaptation is a flow variable.

In the next section, a new specification of the interactions between adaptation and mitigation is proposed. In this new setting, adaptation is both a stock and a flow variable, and the role of adaptive capacity is also crucial.

\section{Adaptation modelling and calibration: the AD-WITCH model}

AD-WITCH links adaptation, mitigation, and climate change damage in an integrated assessment model of the world economy, the energy, and climate system. AD-WITCH builds on the WITCH model (Bosetti et al. 2006, Bosetti et al. 2009), of which it shares the main characteristics. It is an intertemporal, optimal growth model in which forward-looking agents choose the path of investments to maximise a social welfare function subject to a budget constraint. It has a game-theoretic structure and it can be solved in two alternative settings. In the noncooperative setting, the twelve model regions behave strategically with respect to all major economic decision variables - including adaptation and emission abatement levels - by playing a non-cooperative game. This yields a Nash equilibrium, which does not internalise the environmental externality. The cooperative setting describes a first-best world, in which all externalities are internalised, because a benevolent social planner maximises a global welfare 
function $^{2}$. The chosen path of mitigation and adaptation investments can be characterised as optimal. For the present analysis, the cooperative approach is adopted.

Differently from WITCH, AD-WITCH separates residual damage from adaptation expenditures, which become policy variables. Their optimal level is chosen consistently with investments in physical capital, R\&D, and energy technologies. To make adaptation comparable to mitigation, the large number of possible adaptive responses is aggregated into three broad expenditure categories: investment in anticipatory adaptation, expenditure in reactive adaptation, and investment in innovation for adaptation.

The first group gathers measures that require building a stock of defensive capital that must be operational when the damage materialises. Typical examples of these activities are coastal protections. These measures exhibit economic inertia because investments in defensive capital take time before becoming an effective protection capital. Therefore, investments must begin before damages occur. If well-designed, they are effective along the medium-term and long-term. By contrast, reactive adaptation refers to actions that are put in place when the damage effectively materialises because it is a response triggered by damages. Examples falling in this group are the expenditure for air conditioning or the response to climate-related diseases. These actions should be undertaken period by period to accommodate the damages not avoided by either anticipatory adaptation or mitigation. They need to be constantly adjusted to changes in climatic conditions. Innovation activity in adaptation includes R\&D investments that improve adaptation effectiveness. Examples of inventions that ease adaptation are the development and diffusion of climate-resilient crops, the introduction of new vaccines, and the development of information technologies that warn local communities about temperature and precipitation variations.

These adaptation forms have been assembled together into an adaptation tree. Using a set of nested CES (Constant elasticity of substitution) functions, the tree describes the relationship between different adaptation modes (Figure 1). The specific equations are reported in Appendix I.

Total adaptation is a combination of anticipatory and reactive adaptation (top-level nest). In the second nest, reactive adaptation compounds reactive adaptation expenditures and a stock of knowledge in adaptation innovation. The inclusion of R\&D investments into the reactive adaptation

\footnotetext{
${ }^{2}$ AD-WITCH, as well as the WITCH model, also features technology externalities due to the presence of Learning-ByResearching and Learning-By-Doing effects. The cooperative scenario internalises all externalities. For more insights on the treatment of technical change in the WITCH model see Bosetti et al. (2009).
} 
nest may appear counterintuitive, but it is based on a factual observation. The two sectors in which adaptation $R \& D$ has the highest potential are agricultural and health care, which both require reactive forms of adaptation. Adaptation $R \& D$ can be seen as a peculiar form of anticipatory adaptation, which increases the effectiveness of reactive adaptation endogenously.

\section{Figure 1: The adaptation tree in the AD_WITCH model}

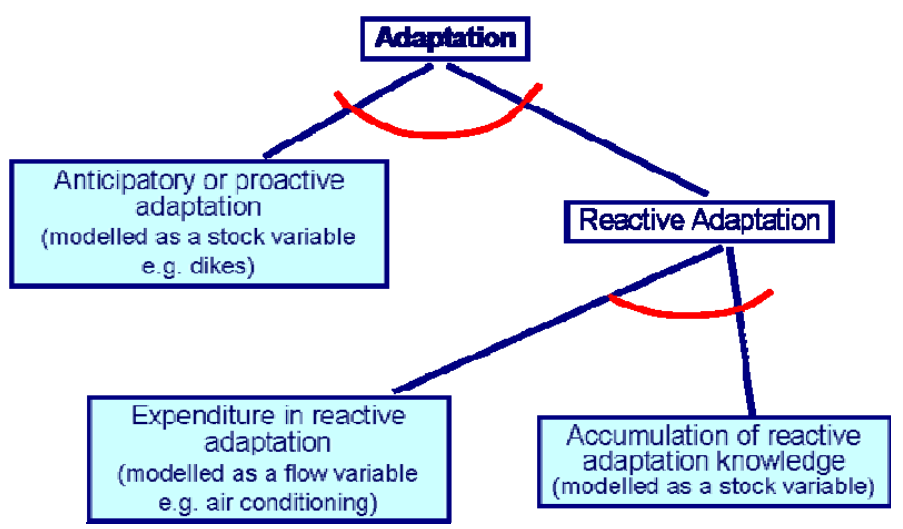

Anticipatory adaptation and knowledge are modelled as a stock of capital, which builds up over time with dedicated investments, following standard accumulation rules. Expenditure on reactive adaptation is modelled as a flow variable. The expenditure needed in each period is driven by the damage faced and it does not depend on the expenditure that occurred in previous periods. The elasticity of substitution between anticipatory and reactive adaptation is set to 0.9 . This neutral choice reflects the balanced position of the literature, supporting the hypothesis of both gross substitutes and complements. Klein et al. (2007) discusses many circumstances in which adaptation and mitigation can complement or substitute each other. Theoretical works ${ }^{3}$ also investigated the relationship

\footnotetext{
${ }^{3}$ See among others, Ingham et al. (2005, 2005a), Lecocq and Shalizi (2007).
} 
between adaptation and mitigation, concluding that the actual relationship is an empirical matter (Kane and Shogren 2000).

Adaptation knowledge and reactive adaptation expenditure are modelled as gross substitutes (the elasticity is equal to 1.4). The intuition is as follows. More investments in R\&D increase the effectiveness of reactive adaptation, reducing the amount of expenditure required to obtain a given adaptation level.

The cost of each adaptation activity is included into the national budget constraint. Investments in anticipatory adaptation, knowledge adaptation, and reactive adaptation expenditure are three additional control variables. These variables compete with alternative uses of regional income for consumption, investments in physical capital, in different energy technologies, and in energy R\&D.

The integration of these three adaptation forms into a unifying framework is the first major contribution to the existing literature, which focused on only reactive (de Bruin, Dellink and Tol 2009) or anticipatory measures (Bosello 2008) and which neglected the role of endogenous innovation in adaptation. The second contribution is an updated calibration of regional adaptation cost and benefit functions. Table 1 summarises the extrapolation of adaptation costs, adaptation effectiveness, and total climate change damages from the literature together with the calibrated values. The calibration point corresponds to the doubling of $\mathrm{CO}_{2}$ concentration, which determines a temperature increase of about $2.5^{\circ} \mathrm{C}$ above pre-industrial levels ${ }^{4}$.

The calibration of the AD-WITCH model integrates the information on climate change damages from WITCH (Bosetti et al. 2006, Bosetti et al. 2009), and Nordhaus and Boyer (2000) with Agrawala and Fankhauser (2008), which provide the most recent and complete assessment of adaptation costs and benefits. These studies have been integrated with area-specific assessments to ground our exercise on the best available quantitative knowledge.

\footnotetext{
${ }^{4}$ Details on the calibration procedure are described in an Appendix available on request.
} 
Table 1. Cost and effectiveness of adaptation. Estimated (from literature) and calibrated (AD-

WITCH) values for $2.5^{\circ} \mathrm{C}$ temperature increase above preindustrial levels

\begin{tabular}{|c|c|c|c|c|c|c|c|c|}
\hline & $\begin{array}{c}\text { Estimated } \\
\text { Adapatation } \\
\text { Costs (\% of } \\
\text { GDP) }\end{array}$ & $\begin{array}{c}\text { Estimated } \\
\text { Adaptation } \\
\text { Effectiveness } \\
\text { (\% of reduced } \\
\text { damage) }\end{array}$ & $\begin{array}{l}\text { Calibrated } \\
\text { Adaptation } \\
\text { Costs in } \\
\text { AD- } \\
\text { WITCH (\% } \\
\text { of GDP) }\end{array}$ & $\begin{array}{c}\text { Calibrated } \\
\text { Adaptation } \\
\text { Effectiveness } \\
\text { in AD- } \\
\text { WITCH (\% of } \\
\text { reduced } \\
\text { damage) }\end{array}$ & $\begin{array}{c}\text { Residual } \\
\text { Damages } \\
\text { in AD- } \\
\text { WITCH } \\
\text { (\% of } \\
\text { GDP) }\end{array}$ & $\begin{array}{c}\text { Total } \\
\text { Damage } \\
\text { in AD- } \\
\text { WITCH } \\
\text { (\% of } \\
\text { GDP) }\end{array}$ & $\begin{array}{c}\text { Total } \\
\text { Damages } \\
\text { in } \\
\text { Nordhaus } \\
\text { and Boyer } \\
\text { (2000) (\% } \\
\text { of GDP) }\end{array}$ & $\begin{array}{c}\text { Total Damages } \\
\text { in the WITCH } \\
\text { Model (\% of } \\
\text { GDP) }\end{array}$ \\
\hline USA & 0.12 & 0.25 & 0.15 & 0.23 & 0.29 & 0.44 & 0.45 & 0.41 \\
\hline WEURO & 0.21 & 0.20 & 0.38 & 0.26 & 1.20 & 1.58 & 2.84 & 2.79 \\
\hline EEURO & 0.54 & 0.34 & 0.17 & 0.35 & 0.38 & 0.55 & 0.70 & -0.34 \\
\hline KOSAU & 0.29 & 0.24 & 0.27 & 0.25 & 0.55 & 0.82 & -0.39 & 0.12 \\
\hline CAJANZ & 0.21 & 0.25 & 0.22 & 0.25 & 0.30 & 0.52 & 0.51 & 0.12 \\
\hline TE & 0.40 & 0.20 & 0.26 & 0.16 & 0.54 & 0.80 & -0.66 & -0.34 \\
\hline MENA & 1.48 & 0.38 & 1.01 & 0.52 & 1.92 & 2.93 & 1.95 & 1.78 \\
\hline SSA & 0.78 & 0.21 & 0.96 & 0.14 & 4.13 & 5.09 & 3.90 & 4.17 \\
\hline SASIA & 0.54 & 0.19 & 0.66 & 0.08 & 4.85 & 5.51 & 4.93 & 4.17 \\
\hline CHINA & 0.22 & 0.22 & 0.08 & 0.14 & 0.42 & 0.50 & 0.23 & 0.22 \\
\hline EASIA & 0.84 & 0.19 & 0.65 & 0.11 & 3.52 & 4.17 & 1.81 & 2.16 \\
\hline LACA & 0.19 & 0.38 & 0.52 & 0.31 & 1.79 & 2.31 & 2.43 & 2.16 \\
\hline
\end{tabular}

Four major points are worth mentioning here. First, we gathered new information on climate change damages consistent with existing adaptation costs and tried to calibrate AD-WITCH on these new values. Second, AD-WITCH is an optimisation model. Therefore, if a region gains from climate change, it would not spend resources on adaptation. Optimising regions would allocate funds to adaptation strategies only if the damage is sufficiently large. Only in this case, adaptation expenditure would bring benefits that justify the costs. As a consequence, in some regions, such as in TE, we need 
to impose a level of damage consistent with observed adaptation costs. Third, the calibrated total climate change costs are reasonably similar to the reference values. Strong inconsistencies were often found between different studies and different data sources. Nevertheless, we tried to guarantee consistency between the three interconnected items: adaptation costs, total damage, and protection levels (or adaptation effectiveness). Adaptation costs and damages move together. A good example is Western Europe (WEURO). It is not possible to lower adaptation costs closer to the reference value without decreasing total damage, which is already below the reference estimate. We are fully aware of this shortcoming which relates to the fourth point. The quantitative assessment of adaptation costs and benefits is still at a pioneering stage. Some areas, such as agriculture and health, in certain regions, especially developing countries, still lack reliable data. In light of this uncertainty, this work aims at replicating the ordinal ranking of adaptation costs and effectiveness rather than at perfectly matching the data.

Despite the effort made to gather new information, AD-WITCH representation of climate change impacts still has some limitations. The description of non-market damages is only partial and AD-WITCH, like most IAMs, abstracts from very rapid warming and large-scale changes of the climate system (system surprises) that for instance drive up climate change costs in Stern (2006). To accommodate these drawbacks and to adhere to recent evidence ${ }^{5}$ pointing at larger climate change damages, we considered a high damage scenario. Discounting is also expected to have major influences on the mitigation and adaptation mix because it governs the perception of present and future ${ }^{6}$ Therefore we also consider different discount rates. The analysis of the optimal mix between mitigation, adaptation, and damage compares a no policy case (non-cooperative, no policy) with four first-best policy scenarios ${ }^{7}$ :

\footnotetext{
${ }^{5}$ Important contributions are Hanemann (2008), the IPCC Fourth Assessment Report (Parry et al. 2007), the Stern Review (Stern 2006), and UNFCCC (2007).

${ }^{6}$ There is a longstanding controversy regarding the PRTP (Weitzman 2001). In line with a long line of economists (Ramsey 1928, Harrod 1948, Solow 1974), Stern (2007) argues on ethical grounds for a near-zero PRTP, while others dismiss this and argue that it is inconsistent with actual individual behaviour (Nordhaus 2007, Weitzman 2007a).

${ }^{7}$ In the non-cooperative scenario, each country maximises regional welfare in the absence of mitigation and adaptation policies. Therefore in a Nash equilibrium, adaptation is not available. The four cooperative scenarios are first-best policy scenarios because the global externality is internalised and adaptation is optimally implemented.
} 
1. LDAM_HDR : "low damage - high discount rate". This is the reference policy scenario. The pure rate of time preference is $3 \%$ declining over time. Climate change damages are those described in Table 1

2. LDAM_LDR: "low damage - low discount rate". The damage is the same as in the previous case but the pure rate of time preference is $0.1 \%$ declining over time, as in Stern (2006)

3. HDAM_HDR: "high damage - high discount rate". The damage is about twice the damage in Table 1 and the pure rate of time preference is $3 \%$ declining over time

4. HDAM_LDR: "high damage - low discount rate". The damage is the same of 3 and the pure rate of time preference is $0.1 \%$ declining over time.

\section{Results}

\subsection{The strategic complementarity between mitigation and adaptation}

Results show clearly that mitigation and adaptation are strategic complements. They are both used in an optimisation setting to reduce climate change damages. Figure 2 shows that in a scenario with moderate damage (low damage high discount rate), optimal abatement leads to global emission reductions ranging between $15 \%$ and 19\% throughout the century. Total adaptation expenditure remains low during the first two decades, it becomes detectable in 2035 (US\$ 2 billion) and afterwards it increases rapidly reaching US\$ 326 billion in 2060, peaking to nearly US\$ 3 trillion in 2100.

The strategic complementarity between adaptation and mitigation emerges also analysing their contribution to damage reduction (Figure 3). Without any action (non-cooperative no policy scenario), residual damage would amount to an annual average of US\$ 584 billion in 2035, and to almost US\$ 14 trillion in 2100. Optimal adaptation alone could reduce residual damages up to 55\% in 2100 averting about US\$ 8 trillion damages (from 4\% to 1.5\% of GWP). Optimal mitigation alone would lower damage up to $20 \%$, avoiding about US\$ 3 trillion worth of damages (from $4 \%$ to $3 \%$ of GWP). When used in combination, the two strategies perform slightly better. 
Figure 2. Mitigation and adaptation in the optimal climate-change strategy

(Low damage High discount rate)

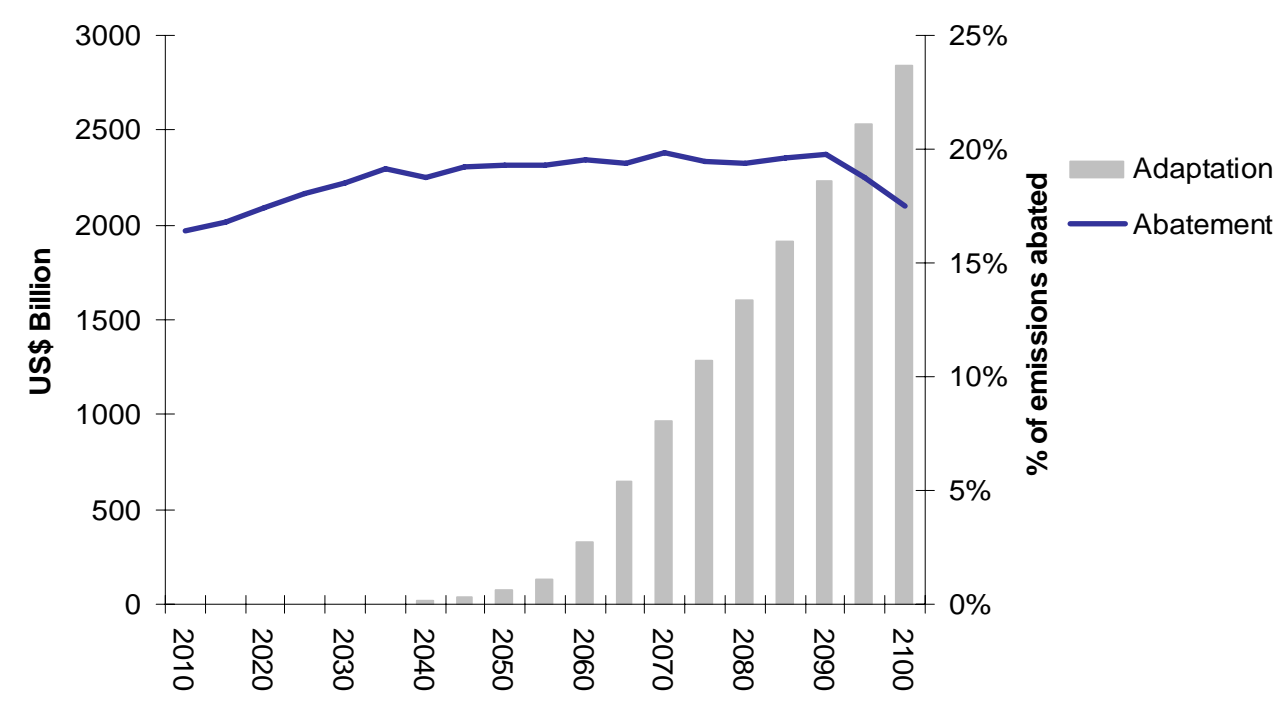

Figure 3: Contribution of adaptation and mitigation to damage reduction (Low damage High discount rate)

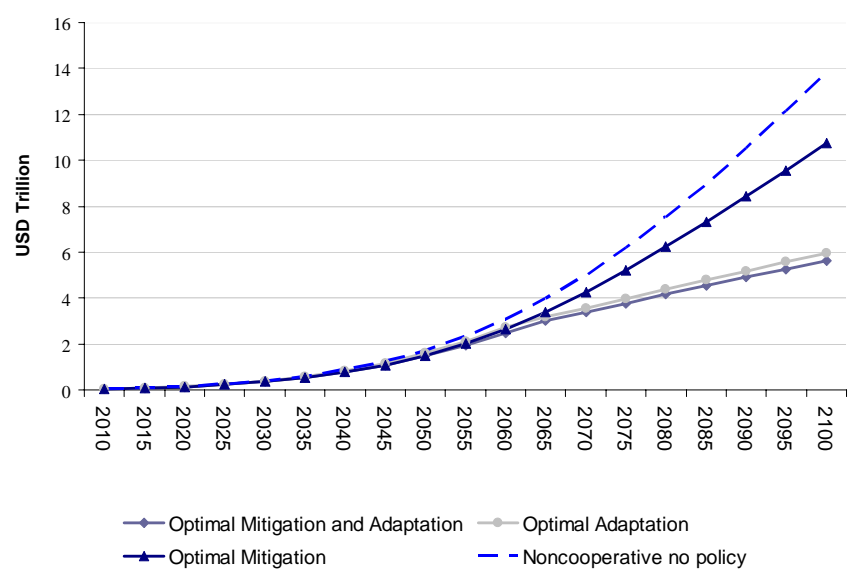

Complementarity is also evident in terms of gross world product (GWP) and global consumption performances. They are both higher when the two strategies are used together than when adaptation or mitigation are implemented alone (Table 2). This is a typical efficiency outcome. In a 
first-best world, if the decision-making process can rely on a wider portfolio of options, then it can achieve higher welfare. Interestingly, when the two strategies are implemented in isolation, the preference among the two depends on the metric used. Adaptation is preferable to mitigation in terms of GWP performance because residual damage with adaptation is much lower than with mitigation. Mitigation performs better than adaptation in terms of consumption, because investments in mitigation are considerably smaller than those in adaptation, especially after 2050. In the reference policy scenario (low damage high discount rate) cumulative undiscounted expenditure on mitigation amounts to US\$ 4 trillion, whereas expenditure on adaptation is much larger, equal to US\$ 73 trillion. Therefore, mitigation induces a smaller crowding out of consumption possibilities.

Table 2: Change in discounted gross world product and consumption (2010-2100 3\% discounting) with respect to the no policy case.

\begin{tabular}{|c|c|c|c|}
\hline & $\begin{array}{c}\text { Optimal adaptation } \\
\text { and mitigation }\end{array}$ & $\begin{array}{r}\text { Optimal } \\
\text { mitigation }\end{array}$ & $\begin{array}{r}\text { Optimal } \\
\text { adaptation }\end{array}$ \\
\hline GWP & $1.27 \%$ & $0.98 \%$ & $1.26 \%$ \\
\hline Consumption & $1.23 \%$ & $1.18 \%$ & $0.49 \%$ \\
\hline
\end{tabular}

Figure 2 emphasises another important characteristic of the optimal mitigation adaptation mix: its time dimension. Mitigation has to start well in advance compared to adaptation. This occurs for two reasons. First, mitigation takes more time to become effective because it works against the carbon cycle inertia. Therefore, to enjoy mitigation benefits within the century, actions need to start immediately. Second, emission reduction is achieved mostly through innovation and decarbonisation of the energy sector. The former option needs large upfront investments, which pay off only in the long-term. The decarbonisation of the energy sector also has a long temporal horizon because of the slow turnover of energy capital.

By contrast, adaptation measures work through a much shorter economic inertia, of at maximum one simulation period, which corresponds to five years in AD-WITCH. Therefore they can be postponed until damages are effectively high. This, consistently with the AD-WITCH damage structure, happens after 2030. Therefore, abatement is substantial when adaptation expenditure is still low. 
In summary, mitigation and adaptation tackle different, but intermingled aspects of climate change. Mitigation is global and long-term, while adaptation is local and short-term. In the case of mitigation, the time span between the costs and benefits can be very large, whereas in the case of adaptation benefits come short after costs ${ }^{8}$. This different timing may affect the policy desirability of mitigation and adaptation measures. Mitigation is characterised by certain, present cost and future, uncertain benefit ${ }^{9}$, which make mitigation more sensitive to subjective assumptions in policy decision making, such as the discount rate.

All this said, adaptation appears by far the most effective damage-reducing strategy and attracts the largest amount of resources. However, Figure 4 suggests why more ambitious mitigation policies can be needed.

\section{Figure 4: Contribution of adaptation and mitigation to damage temperature increase (Low damage High discount rate)}

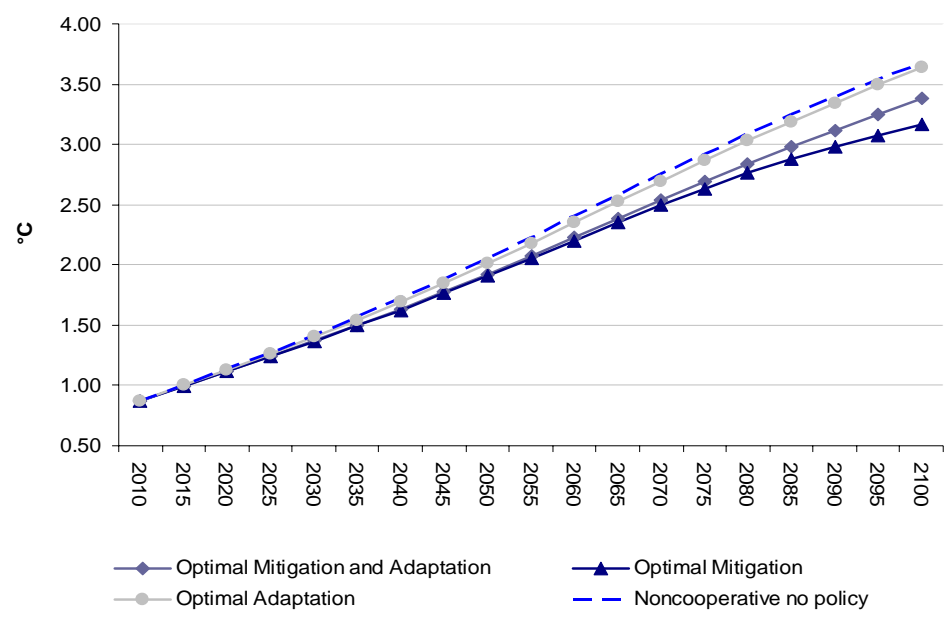

\footnotetext{
${ }^{8}$ It has to be stressed that economic inertias can be long as well e.g. implementing coastal protection interventions can take many years (or even decades) and that adaptation may not be immediately effective as in the case for anticipatory adaptation. However, the time lag is always lower than in the case of mitigation.

${ }^{9}$ Fussel and Klein, (2006) note that monitoring mitigation effectiveness is easier than monitoring adaptation. They refer to the fact that it is easier to measure emission reduction than quantify the avoided climate change damage due to adaptation. They do not refer to the quantification of the avoided future damage due to emission reduction.
} 
Although effective at reducing damages, adaptation does nothing to control temperature increase. Only mitigation can do this. So, it is the only viable strategy to avoid catastrophic, potentially irreversible and un-adaptable damages triggered by the warming process. Mitigation is thus justified on the basis of the precautionary principle when low probability, but high damaging outcomes could occur. It could however appear less appropriate in a smooth world presenting only changes in average conditions like those represented by AD-WITCH (see on this Weitzman 2007a, 2009). Note however that also in this case abatement effort is far from negligible (15\% - 19\% along the century) even though it is not comparable to the requirements needed to stabilise temperature $2^{\circ} \mathrm{C}$ above preindustrial levels.

\subsection{The economic trade-off}

The strategic complementarity between mitigation and adaptation implies also an economic trade-off. Given that both reduce climate change damage, resources can be allocated more efficiently on this wider portfolio of strategies. Because resources are scarce, increasing those for one usage implies that less is available for the other one (see also Tol 2005, Lecoq and Shalizi 2007). Moreover, successful adaptation reduces the marginal benefit of mitigation and a successful mitigation effort reduces the damage to which it is necessary to adapt. The two can be viewed as competing strategies, but also as imperfectly substitutable normal goods in the welfare maximisation problem, a concept already emphasised by Ingham et al. (2005, 2005a). Figures 5 illustrates this idea.

When adaptation is optimally implemented, the need and the resources to mitigate are lower (left-panel). The temporal pattern of the trade-off between mitigation and adaptation depends on the optimal path of adaptation expenditure. Adaptation becomes economically attractive only when damages become sufficiently large. Until 2030 adaptation expenditure is still very low and the emission paths with and without adaptation are very close. As a consequence, it influences the optimal abatement decision significantly only in the second half of the century. The crowding out expands over time. Adaptation induces higher $\mathrm{CO}_{2}$ emissions by $10 \%$ in 2055 and by $30 \%$ in 2100 . 
Figure 5. The economic trade-off between adaptation and mitigation

(Low damage High discount rate)
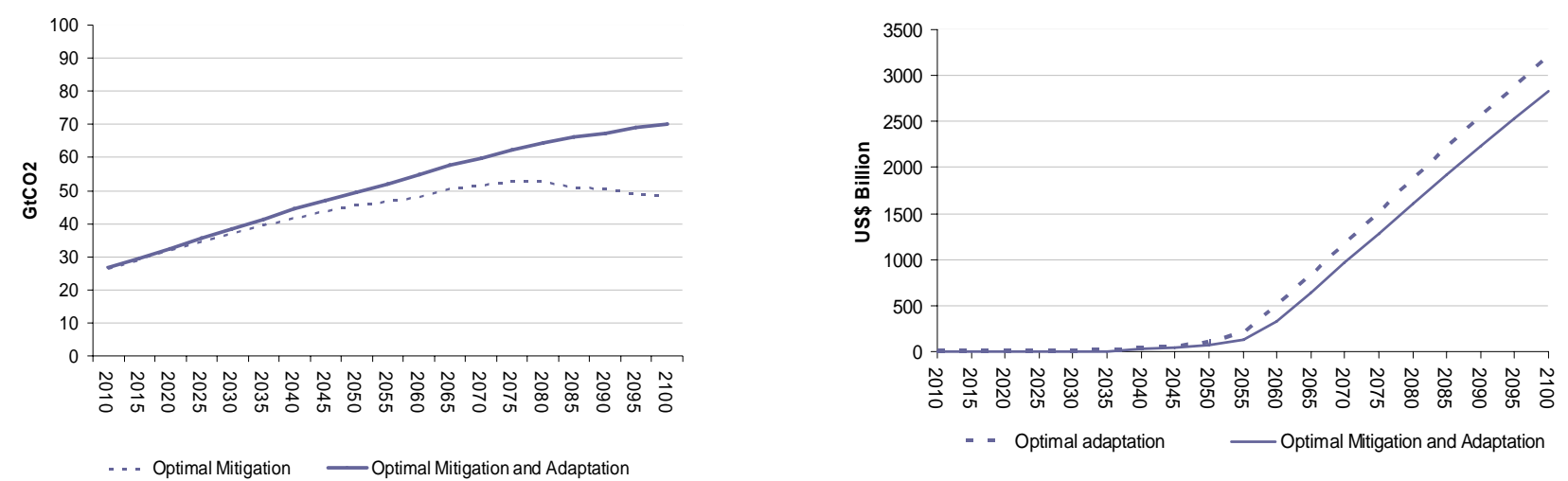

Symmetrically, mitigation reduces the need to adapt (right-panel). It limits temperature increase (Figure 4) and lowers the amount of damage that must be accommodated by adaptation. Without mitigation, total adaptation expenditure (cumulative undiscounted) is $16 \%$ higher than with mitigation. Mitigation crowds out adaptation especially during the first half of the century, from $24 \%$ in 2050 to $12 \%$ in 2100.

To conclude the section, Table 3 analyses the sensitivity of the mitigation adaptation mix to damage and discounting. Unambiguously when the discount rate is low, mitigation emerges as the strategy that contributes relatively more to damage reduction. The effect of a lower discounting is to increase the weight of future damages. Therefore mitigation, which is more effective on the distant future, is preferred. In addition to catastrophic uncertainty, low discount rates are another factor justifying not only higher abatement, but also a relatively more intense use of mitigation than adaptation. On the contrary, adaptation prevails when damages and the discount rate are high. When present and future climate change damages double (high damage scenarios) both mitigation and adaptation efforts increase, ${ }^{10}$ but in relative terms, adaptation, which deals more effectively on the near term, is preferred. This effect is strengthened by high discount rates: larger damages that would prevail

\footnotetext{
${ }^{10}$ Note that this is exactly the typical income effect with normal goods.
} 
in the second part of the century are not perceived by the maximising agent and mitigation is penalised in favour of adaptation because of the longer time distance between expenditure and returns.

Table 3. Sensitivity analysis on the optimal mix between mitigation and adaptation

\begin{tabular}{|l|cccc|}
\hline \multicolumn{5}{|c|}{ Expenditure allocation between adaptation and mitigation } \\
\hline \multicolumn{4}{|c|}{ Relative contribution to damage reduction (2010 - $\mathbf{2 1 0 0}$ cumulative undiscounted) } \\
Low damage & Low damage & High damage high & High damage low discount \\
& $\begin{array}{c}\text { high discount } \\
\text { rate }\end{array}$ & $\begin{array}{c}\text { low discount } \\
\text { rate }\end{array}$ & discount rate & rate \\
Mitigation & $10 \%$ & $40 \%$ & $9.1 \%$ & $43 \%$ \\
Adaptation & $34 \%$ & $20 \%$ & $53 \%$ & $30 \%$ \\
Total & $44 \%$ & $60 \%$ & $62 \%$ & $73 \%$ \\
\hline
\end{tabular}

\subsection{Decomposing the adaptation bundle: regional results}

This section provides insights on regional specificities and on the optimal mix between different adaptation modes. A broad disaggregation between OECD and non-OECD countries highlights some common features, and also some important differences. Table 4 summarises the optimal composition of the different adaptation types in the developed and developing countries in the two extreme scenarios: an optimistic scenario characterised by current and future moderate damages (low damage high discount rate) and a pessimistic scenario with high current and future damages (high damage low discount rate). 
Table 4: Adaptation expenditure by type. Cumulated undiscounted

\begin{tabular}{|c|c|c|c|c|c|c|c|c|}
\hline & \multicolumn{4}{|c|}{$\begin{array}{c}\text { Moderate damage } \\
\text { (Low damage high discount rate) }\end{array}$} & \multicolumn{4}{|c|}{$\begin{array}{c}\text { High damage } \\
\text { (High damage low discount rate) }\end{array}$} \\
\hline & \multicolumn{2}{|c|}{ Non-OECD } & \multicolumn{2}{|c|}{ OECD } & \multicolumn{2}{|c|}{ Non-OECD } & \multicolumn{2}{|c|}{ OECD } \\
\hline & USD Trill. & $\begin{array}{c}\% \text { over } \\
\text { total }\end{array}$ & USD Trill. & $\begin{array}{c}\% \text { over } \\
\text { total }\end{array}$ & USD Trill. & $\begin{array}{c}\% \text { over } \\
\text { total }\end{array}$ & USD Trill. & $\begin{array}{c}\% \text { over } \\
\text { total }\end{array}$ \\
\hline \multicolumn{9}{|c|}{ 2010-2050 } \\
\hline Anticipatory adaptation & 0.59 & $85 \%$ & 0.01 & $97 \%$ & 3.86 & $78 \%$ & 5.51 & $92 \%$ \\
\hline Reactive adaptation & 0.10 & $15 \%$ & 0.00 & $2 \%$ & 1.09 & $22 \%$ & 0.27 & $5 \%$ \\
\hline Innovation for adaptation & 0.00 & $0 \%$ & 0.00 & $1 \%$ & 0.02 & $0 \%$ & 0.18 & $3 \%$ \\
\hline Total & 0.69 & & 0.01 & & 4.98 & & 5.96 & \\
\hline \multicolumn{9}{|c|}{ 2055-2100 } \\
\hline Anticipatory adaptation & 24.69 & $42 \%$ & 12.36 & $88 \%$ & 46.03 & $49 \%$ & 28.46 & $88 \%$ \\
\hline Reactive adaptation & 33.54 & $58 \%$ & 1.39 & $10 \%$ & 47.29 & $51 \%$ & 3.04 & $9 \%$ \\
\hline Innovation for adaptation & 0.07 & $0 \%$ & 0.31 & $2 \%$ & 0.18 & $0 \%$ & 0.88 & $3 \%$ \\
\hline Total & 58.30 & & 14.06 & & 93.50 & & 32.38 & \\
\hline \multicolumn{9}{|c|}{ 2010-2100 } \\
\hline Anticipatory adaptation & 25.28 & $43 \%$ & 12.37 & $88 \%$ & 49.89 & $51 \%$ & 33.97 & $89 \%$ \\
\hline Reactive adaptation & 33.64 & $57 \%$ & 1.39 & $10 \%$ & 48.38 & $49 \%$ & 3.31 & $9 \%$ \\
\hline Innovation for adaptation & 0.07 & $0 \%$ & 0.31 & $2 \%$ & 0.20 & $0 \%$ & 1.06 & $3 \%$ \\
\hline Total & 58.99 & & 14.07 & & 98.47 & & 38.35 & \\
\hline
\end{tabular}

In both OECD and non-OECD regions expenditure in anticipatory adaptation starts before reactive adaptation and it constitutes the majority of adaptation investments in the first half of the century. What really differs is the composition of the adaptation mix. While in non-OECD countries the weight of reactive and anticipatory measures is rather balanced (throughout the period they 
contribute $57 \%$ and $49 \%$ to total adaptation expenditure), in OECD countries anticipatory measures clearly prevail (they constitute $88 \%$ of total expenditure on adaptation).

This different composition of adaptation responses depends on two factors: the regional characteristics of climate vulnerability and the level of economic development. In OECD countries, the higher share of climate change damages originates from loss of infrastructure and coastal areas, whose protection requires a form of adaptation that is largely anticipatory. In non-OECD countries, climate change relatively hits more agriculture, health, and the use of energy for space heating and cooling. These damages can be accommodated more effectively through reactive measures.

Second, OECD countries are richer. Thus, they can give up more easily their present consumption to invest in adaptation measures that will become productive in the future. By contrast, non-OECD countries are compelled by resource scarcity to act in emergency. This reasoning also explains why more than $80 \%$ of world $\mathrm{R} \& \mathrm{D}$ expenditure on adaptation takes place in the developed countries: because it is a costly investment, it is undertaken by the regions that have a comparative advantage.

Another clear message from Table 4 is the difference in adaptation needs between developed and developing countries. The second are hit more severely by climatic change and, depending on the scenario, their expected adaptation expenditure is two to four times larger than that of developed countries. This expenditure is concentrated and dramatically increasing in the second half of the century, driven by growing climate change damages. In 2050 it could amount to US\$ 78 billion, in 2065 it will be above US\$ 500 billion and peak above US\$ 2 trillion by the end of the century.

Larger adaptation needs and the lack of innovative capacity in developing countries create a mismatch between where adaptation can be carried out and where it is mostly needed. The mismatch depends on exposure and capacity to adapt to change damages, which are unrelated to the geography of historical responsibilities. This suggests a specific direction for international cooperation on adaptation. It should aim at alleviating damages not directly caused by the affected community, fulfilling the need for equity. But what can be the size of the cooperation effort required? Assuming that a minimal equity criteria is equalising the ratio of total adaptation expenditure over GDP, the transfers needed from the OECD to non-OECD would amount to an annuity of US\$ 470 billion. Larger damages and/or a lower 
discounting would require larger transfers ${ }^{11}$. These transfers are enormous. To put the numbers in perspective, it is sufficient to consider that in 2007 total official development aids were US\$ 100 billion. Transfers for financing adaptation appear even larger considering that they should be additional to the usual development aids.

\section{Summary and conclusions}

This paper has investigated how mitigation and adaptation should be combined in an integrated policy framework, using a newly developed model that closes the loop between damages, mitigation, and adaptation. Compared to the increasing but still limited literature in this area, two major innovations are offered: a more sophisticated description of adaptation strategies (reactive adaptation, anticipatory adaptation, and $R \& D$ in adaptation) that are for the first time compounded in a unified structure, and a newly updated calibration of regional adaptation costs and effectiveness.

The cost-benefit analysis performed with this set-up confirms that the joint implementation of mitigation and adaptation is welfare improving. Both options are needed because they can reduce climate change vulnerability through two different, but complementary manners. The first channel decreases its causes while the second channel addresses its effects. The two strategies are strategic complements and they both need to be part of a cost-efficient climate change strategy. The dual of this complementarity is the economic trade-off. The optimal allocation of scarce resources over more strategies implies that adaptation partly crowds out mitigation and vice-versa. This is consistent with the theoretical and the applied literature in the field.

It is also shown that in a world without catastrophic events and where the decision maker has a strong preference for the present, adaptation is unambiguously the preferred option. The optimal climate change strategy would imply a $44 \%$ damage reduction, $78 \%$ of which accomplished by adaptation and only the remaining $22 \%$ by mitigation. This would imply an emission reduction ranging from $15 \%$ to $19 \%$ compared to the baseline, leading to a temperature increase of about $3^{\circ} \mathrm{C}-3.4^{\circ} \mathrm{C}$ above pre-industrial levels.

These results indicate that cost-benefit criteria, applied in a smooth-damage, perfectinformation context as in the present paper hardly justify strong reductions as those currently discussed

\footnotetext{
${ }^{11}$ The figure proposed is an average estimate computed during the period 2010-2100. Funding adaptation would require a relatively small transfer from OECD to NON OECD until 2030, that will increase sharply afterwards.
} 
in international policy arena. Even assuming larger, but sill continuous and smooth damages, optimal abatement would limit temperature increase at best to $2.5^{\circ} \mathrm{C}$, thus above the $2^{\circ} \mathrm{C}$ EU target. However, this does not mean that aggressive mitigation is not necessary, but that it can be justified on the basis of precautionary considerations in the presence of catastrophic uncertainty.

This conclusion may suggest a simplified approach to the current debate on how to couple mitigation and adaptation. Aggressive mitigation should be the starting point. Its characteristics should be determined on the basis of the precautionary principles and independently on adaptation because adaptation cannot avoid irreversibility. Then, adaptation efforts should be optimally designed, consistently with mitigation, as a residual strategy addressing the damage not accommodated by mitigation. This idea will be explored in a future research.

The present research also stresses that adaptation needs, both in developed and developing countries would be massive, especially in the second half of the century. However, most of the adaptation burden will be on the developing countries, with an expenditure gap increasing over time. Developing countries are more exposed but less capable of adapting to a damage, for which they bear little responsibility. International cooperation is thus required to distribute more equally the burden of adaptation. Specific indications on the direction of international adaptation aid can be drawn by analysing the regional composition of the adaptation basket. Richer countries could help developing countries by supporting $R \& D$ in adaptation-related technologies and preventive actions in which the developing countries show a structural deficit. The financial flows associated are expected to be huge. For instance, to equalise adaptation expenditure per unit of GDP throughout century, OECD should transfer to non-OECD an annuity of USD 470 billion. These transfers should be additional to current official development aid.

Finally, the present analysis also highlights the time composition of the optimal climate change strategy. Mitigation has to be anticipated because environmental and technological inertia delays its benefits far in the future. On the contrary, adaptation can be postponed until damages are effectively higher. Similarly, among different adaptation strategies those assuming the form of stocks, either of knowledge or of defensive capital, need to be anticipated. This result provides some guidelines on how to best allocate climate change funds. In the short-run they should be tilted towards mitigation. 


\section{References}

Agrawala, S. and S. Fankhauser, (eds.) 2008. Economics aspects of adaptation to climate change. Costs, benefits and policy instrument. OECD

Bosello, F. 2008. “Adaptation, Mitigation and Green R\&D to Combat Global Climate Change. Insights From an Empirical Integrated Assessment Exercise,” CMCC Research Paper No.20

Bosetti, V., C. Carraro, M. Galeotti, E. Massetti and M. Tavoni 2006. "WITCH: A World Induced Technical Change Hybrid Model,” The Energy Journal. Special Issue on Hybrid Modeling of Energy-Environment Policies: Reconciling Bottom-up and Top-down 13-38

Bosetti, V., C. Carraro, R. Duval, A. Sgobbi and M. Tavoni 2009. "The Role of R\&D and Technology Diffusion in Climate Change Mitigation: New Perspectives using the WITCH Model,” OECD Working Paper No. 664

Bosetti, V., De Cian, E. Sgobbi, A. and Tavoni, M. 2009. "The 2008 WITCH model: new model features and baseline,” FEEM Working Paper No. 95.09, Oct 2009.

Buonanno, P., Carraro, C., Castelnuovo, E. and M. Galeotti 2000. "Efficiency and Equity of Emission Trading with Endogenous Environmental Technical Change,” in Carraro C. (ed.), Efficiency and Equity of Climate Change Policy, Dordrecht: Kluwer Academic Publishers

Carraro C., E. Massetti (2010). “Two good news from Copenhagen?” 15 January 2010 at http://www.voxeu.org/index.php?q=node/4490

de Bruin K.C., Dellink, R.B. and R.S.J. Tol 2009. “AD-DICE: An Implementation of Adaptation in the DICE Model,” Climatic Change 95:63-81

de Bruin K.C., Dellink, R.B. and S. Agrawala 2009. “Economic aspects of adaptation to climate change: integrated assessment modelling of adaptation costs and benefits,” OECD Environment Working Paper, No. 6

Füssel H.M. and Klein R.J.T., 2006. “Climate Change Vulnerability Assessments: An Evolution of Conceptual Thinking”, Climatic Change, 75, 301-329.

Harrod, R-F. 1948. “Towards a Dynamic Economics: Some recent developments of economic theory and their application to policy”, London: Macmillan. 
Hanemann, W.M. 2008. "What is the Cost of Climate Change?," CUDARE Working Paper No. 1027, University of California, Berkeley

Hope, C., Anderson, J. and P. Wenman 1993. "Policy Analysis of the Greenhouse effect: an Application of the PAGE model,” Energy Policy 21: 327-338

Hope, C. and Newbery, D. 2006. "Calculating the social cost of carbon,” Electricity Policy Research Group Working Papers, No. EPRG 07/20, Cambridge, UK, University of Cambridge

Ingham, A., Ma, J. and Ulph A.M. 2005. "Can Adaptation and Mitigation be Complements?,” Working Paper 79, Tyndall Centre for Climate Change Research

Ingham, A., Ma, J. and Ulph A.M. 2005a. "How do the Costs of Adaptation affect Optimal Mitigation when there is Uncertainty, Irreversibility and Learning?,” Working Paper 74, Tyndall Centre for Climate Change Research

Kane, S. and J. Shogren 2000. "Linking Adaptation and Mitigation in Climate Change Policy,” Climatic Change 45: 75-102

Klein, R.J.T., S. Huq, F. Denton, T.E. Downing, R.G. Richels, J.B. Robinson, F.L. Toth, 2007. Inter-relationships between adaptation and mitigation. Climate Change 2007: Impacts, Adaptation and Vulnerability. Contribution of Working Group II to the Fourth Assessment Report of the Intergovernmental Panel on Climate Change, M.L. Parry, O.F. Canziani, J.P. Palutikof, P.J. van der Linden and C.E. Hanson, Eds., Cambridge University Press, Cambridge, UK, 745-777

Lecoq, F. and Z. Shalizi 2007. "Balancing Expenditures on Mitigation and Adaptation to Climate Change: An Explorations of Issues Relevant for Developing Countries,” World Bank Policy Research Working Paper 4299

Nordhaus, W.D. 1994. Managing the Global Commons: The economics of the greenhouse effect. The MIT Press

Nordhaus, W.D. and J.G. Boyer 2000. Warming the World: the Economics of the Greenhouse Effect. The MIT Press

Nordhaus, W.D. 2007. A Review of the Stern Review on the Economics of Climate Change, Journal of Economic Literature, Vol. XLV (September 2007), pp. 686-702 
Parry, M., O. Canziani, J. Palutikof, P. van der Linden, C. Hanson (eds.) 2007. Climate Change 2007. Impacts, Adaptation and Vulnerability. Contribution of Working Group II to the Fourth Assessment Report on Climate Change. Cambridge University Press

Parry, M. 2009. “Closing the loop between mitigation, impacts and adaptation,” Climatic Change, 96: 23-27

Ramsey, F. 1928. “A Mathematical Theory of Saving”, Economic Journal, 38 (152): 543-559.

Solomon, S., D. Qin, M. Manning, Z. Chen, M. Marquis, K.B. Averyt, M. Tignor and H.L. Miller (eds.) 2007. Climate Change 2007: The Physical Science Basis. Contribution of Working Group I to the Fourth Assessment Report of the Intergovernmental Panel on Climate Change. Cambridge University Press

Solow, R. 1974. "The Economics of Resources or the Resources of Economics”, American Economic Review 64(2):1-14

Stern, N. 2006. The Economics of Climate Change. The Stern Review.Cambridge University Press

Tol, R.S.J. 2005. “Adaptation and Mitigation: Trade-Offs in Substance and Methods”, Environmental Science and Policy, 8 (6), 572-578.

UNFCCC 2007. Investments and Financial Flows to Address Climate Change. Climate Change Secreteriat, Bonn

Weitzman, M.L. 2001. “Gamma Discounting”, American Economic Review, 91(1), 260-271, March 2001

Weitzman, M.L. 2007. “Subjective Expectations and Asset-Return Puzzles," American Economic Review, 97(4), 1102-1130

Weitzman, M.L. 2007a. “A Review of The Stern Review on the Economics of Climate Change,” Journal of Economic Literature, 45 (3), 703-724

Weitzman, M.L. 2009. “On Modeling and Interpreting the Economics of Catastrophic Climate Change," Review of Economics and Statistics, 91(1) (February 2009): 1-19. 


\section{Appendix I. Incorporating adaptation into the Witch model}

In the present study, three different types of adaptation strategies have been considered: proactive or anticipatory adaptation, reactive adaptation, and innovation activity in adaptation.

The starting point for their implementation is the original WITCH climate-change damage specification:

$Y N_{n, t}=\frac{1}{1+C C D_{n, t}} \cdot Y G_{n, t}$

Where the damage from climate change (time and region specific) entails a GDP loss measured by a gap between gross or potential (without climate damage) output, $Y G$, and net output, $Y N$.

Following the specification described in Nordhaus and Boyer (2000), the climate change damage function, $C C D_{n, t}$ is a reduced-form relationship between temperature and output :

$C C D_{n, t}=\theta_{1 n} \cdot T_{t}+\theta_{2 n} T_{t}^{\gamma_{n}}$

Its parameters have been calibrated to replicate a percentage change in GDP loss in response to a $2.5^{\circ} \mathrm{C}$ temperature increase above pre-industrial levels. The exponent $\gamma$ is greater than one to model the convex relationship in temperature.

It is worth recalling that the calibration of (2) compounds two components of climate-change induced GDP losses, namely adaptation costs and residual damages. We changed this in two ways: we explicit the role of adaptation in reducing climate change damage in (2) and we separated from (2) the cost component of adaptation. The climate change damage function with adaptation becomes:

$C C D A_{n, t}=f\left(A D A P T_{n, t}, C C D_{n, t}\right)=\frac{1}{1+A D A P T_{n, t}} \cdot C C D_{n, t}^{\prime}$

In equation (3), an increase in adaptation activities as a whole $\left(A D A P T_{n, t}\right)$ reduces the negative impact from climate change, thus its negative effect on gross output. Note that the way in which adaptation appears in (3) is the simplest functional form presenting, by construction, there are two nice properties: it is bounded between 0 and 1 . An infinite amount of resources diverted to adaptation can reduce the residual climate change damage to 0 at the maximum. If no adaptation is undertaken 
damages are felt entirely by the economic systems. In addition, adaptation exhibits decreasing marginal productivity, thus additional resources to adaptation become less and less effective in reducing damage.

As mentioned before, different types of adaptive strategies can be chosen: proactive, reactive and innovation. $A D A P T_{n, t}$ is thus decomposed into these three components by a sequence of Constant Elasticity of Substitution (CES) nests. The choice of the CES specification is determined by its great flexibility in representing the different degrees of substitutability/complementarity among its components. Simply adjusting the CES exponents, alternative assumptions about the relationships between different adaptation strategies can easily be tested.

In the first CES nest, total adaptation, $A D A P T_{n, t}$, is a combination of proactive $S A D_{n, t}$ and reactive $F R A D_{n, t}$ adaptation according to:

$$
A D A P T_{n, t}=\mathrm{A}_{A D A}\left(\alpha_{1, n} S A D_{n, t}^{\rho_{A D A}}+\alpha_{2, n} F R A D_{n, t}^{\rho_{A D A}}\right)^{1 / \rho_{A D A}}
$$

Proactive adaptation $S A D_{n, t}$ is modelled as a stock of adaptation capital, which accumulates over time with an adaptation-specific investments, $I A_{n, t}$, according to a standard discrete-time law of motion:

$S A D_{n, t}=(1-\delta) \cdot S A D_{n, t-1}+I A_{n, t}$

The stock depreciates at a rate $\delta$. Services from reactive adaptation, $F R A D_{n, t}$, are described by a second CES nest compounding reactive adaptation expenditures strictu-sensu, ERAD ${ }_{n, t}$, and a stock of adaptation knowledge $K R A D_{n, t}$, which represents the innovation in adaptation. It is defined as follows:

$$
F R A D_{n, t}=\mathrm{B}_{S R A D}\left(\beta_{1, n} K R A D_{n, t}^{\rho_{R A D}}+\beta_{2, n} E R A D_{n, t}^{\rho_{R A D}}\right)^{1 / \rho_{R A D}}
$$

Accumulation of adaptation knowledge follows a typical law of motion depending upon investment in adaptation knowledge $I K R A D_{n, t}$ and a depreciation rate:

$$
K R A D_{n, t}=(1-\delta) \cdot K R A D_{n, t-1}+I K R A D_{n, t}
$$

To summarise, proactive adaptation and innovation in adaptation activities are modelled as "stock variables", and expenditure in reactive adaptation is modelled as a "flow variable". Note from (6) and (7) that reactive adaptation, described at the beginning of this annex as a flow of expenditure, is in reality modelled as a CES nest combining a stock and a flow variable. 
This choice is driven by a factual observation: the two main categories of $R \& D$ expenditures that can be referred to adaptation are research in agriculture (mainly aiming to develop weather resistant crops specimen) and in the health sector (aiming to develop new vaccines). Both expenditures, even though not necessarily spurred by climate change, help defeat diseases like vector borne diseases with a link to climate. Both research activities increase the effectiveness of adaptation measures, in agriculture and health care, and are typically reactive ${ }^{12}$.

The CES specification allows us to test different substitutability or complementarity assumptions between direct expenditures in reactive measures and investments to make these measures more effective. Different parameterisations will be tested in a set of sensitivity analyses.

So far we have discussed how to model the effectiveness of different forms of adaptation. The cost of adaptation is also accounted for, by including the cost of the three adaptation measures into the national income identity, which becomes:

$$
Y N_{n, t}=C_{n, t}+I_{n, t}+I R \& D_{n, t}+\sum_{J} I_{j_{n, t}}+E R A D_{n, t}+I A_{n, t}+I K R A D_{n, t}
$$

In eq. (8), expenditure in reactive adaptation, investments in adaptation capital and knowledge compete with the alternative uses of income in the WITCH model, i.e. consumption $C_{n, t}$, investment in physical capital $I_{n, t}$, investment in other forms of technical progress $I R \& D_{n, t}$ and in energy technologies $I_{j_{n, t}}$.

To conclude, having made explicit in (2) the component referred to the effectiveness of adaptation and having switched the adaptation cost component to (8), what remains in the climate change damage function $C C D A_{n, t}$ in (3) is now residual damage. Accordingly, the component $C C D_{n, t}^{\prime}$ must be defined by a new parameterisation of (2), which excludes adaptation costs. The calibration process of (3) and of all the new equations of the AD-WITCH model is described in Annex II.

Finally, residual damage is defined as the difference between gross and net output, i.e. from equation (1) we have:

\footnotetext{
12 This explanation may not hold for health care expenditure that can be preventive, however the data we have refer to treatment cost of diseases which is obviously reactive.
} 


$$
Y G_{n, t}-Y N_{n, t}=C C D_{n, t} Y N_{n, t}=R D_{n, t}
$$

From which, using (2) and (3), the residual damage is:

$$
R D_{n, t}=Y N_{n, t} \frac{1}{1+A D A P T_{n, t}}\left(\theta_{1 n} T_{t}+\theta_{2 n} \cdot T_{t}^{\gamma 3 n}\right)
$$

